SELF-ESTEEM AND SELF-EFFICACY OUTCOMES FOR UNEMPLOYED INDIVIDUALS ATTENDING OCCUPATIONAL SKILLS TRAINING PROGRAMS

Authors:

Peter A. Creed

Tracey D. Bloxsome

Karla Johnston

Affiliation:

School of Applied Psychology

Griffith University, Gold Coast

Key Words:

Unemployed

Self-esteem

Job-search Self-efficacy

Behavioural plasticity

Training climate

Address for Correspondence:

Dr Peter Creed

School of Applied Psychology

Griffith University

PMB 50 GCMC

Gold Coast 9726

Australia

p.creed@mailbox.gu.edu.au 


\title{
SELF-ESTEEM AND SELF-EFFICACY OUTCOMES FOR UNEMPLOYED INDIVIDUALS ATTENDING OCCUPATIONAL SKILLS TRAINING PROGRAMS
}

\begin{abstract}
This paper reports on immediate and long-term well-being and confidence outcomes for unemployed individuals who attended occupational skills/personal development training courses. Results for unemployed trainees were compared with an unemployed waiting-list control group. Outcomes investigated were self-esteem and job-search self-efficacy. Immediate benefits were identified for both dependent variables, and some support was identified for long-term benefits in job-search self-efficacy. Behavioural plasticity effects were demonstrated, with participants with lower levels of self-esteem and lower levels of job-search self-efficacy pre-course responding differently to training than those with higher levels at that time. Outcomes were also examined in relation to the impact of the psychosocial climate of the training environment. Self-esteem and confidence levels at the end of the courses were associated with perceptions of the actual training environment. Practical implications are discussed, and outcomes are related to the theoretical explanations for changes in well-being for unemployed people.
\end{abstract}




\section{Extent of Unemployment Problem}

High levels of unemployment have been a major social problem across many developed countries since the early 1970s. For example, unemployment rates between 1993-1997 averaged $8.8 \%$ in the UK, $10 \%$ in Canada, $5.8 \%$ in the US, and almost $12 \%$ in France (Eatwell, 1999). During the same period in Australia the average unemployment rate was $9.3 \%$, and currently hovers around $7 \%$ of the labour force (ABS, 2000a). This approximates to some 700,000 people being out of work in Australia, with more than one quarter of these people being unemployed for periods of 12 months or longer (ABS, 2000b). This picture is worsened if the large number of estimated "hidden unemployed" are also included (Sheehan, 1980).

\section{Impact of Unemployment on the Individual}

There is now compelling evidence that unemployment is associated with decreases in psychological well-being (see Winefield, 1995 for a recent review). Unemployed people, for example, report elevated levels of psychological distress (Henwood \& Miles, 1987) and depression (Feather \& O’Brien, 1986), and present with lower levels of confidence (Wanberg, Watt \& Rumsey, 1996) than their employed counterparts. Further, the evidence from longitudinal studies is that it is the experience of unemployment that causes the deterioration in well-being, rather than it being employed people with poorer mental health disproportionately moving into unemployment (e.g., Winefield \& Tiggemann, 1990).

\section{Explanations for Deteriorating Well-being in Unemployed People}

Several specific unemployment theories have been proposed to account for the poor well-being in the unemployed. The most influential of these is the Deprivation Model 
proposed by Jahoda (1981). Jahoda argued that employment provided both manifest (associated with financial income) and latent functions (associated with meeting psychological needs). People are driven to employment to attain manifest functions, but while employed also benefit from the latent functions of time structure, social contact, common goals, status, and enforced activity. Deprivation of employment leads to deprivation in both manifest and latent functions, but it is the loss of the latent functions that operates to reduce well-being. This position has been expanded and elaborated by Warr (1987) who, for example, also offered an explanation for the effects of differing levels of the latent and manifest functions.

The second influential explanation for the psychological deterioration is the Personal Agency theory proposed by Fryer (1986). Fryer considered individuals to be, "socially embedded agents ... actively striving for purposeful determination...” (Fryer, 1995; p. 270). He argued that the main negative consequence of unemployment was the loss of the manifest function (loss of income). This loss inhibits the exercise of personal agency and makes it difficult or impossible for the individual to plan and organize personally satisfying lifestyles that are necessary for the development and maintenance of well-being.

\section{Operationalisation of Well-being as Self-esteem}

Well-being has been widely operationalised in the occupational literature as self-esteem (Feather, 1990). Experimental research has demonstrated that self-esteem is not a stable trait, but rather is likely to be effected by the immediate situation and the motives of the individual (Bednar, Wells \& Peterson, 1989). A consistent association has been demonstrated between self-esteem and occupational status, with unemployed people typically faring more poorly than their in-work counterparts (e.g., Patton \& Noller, 1984; Shamir, 1986; Winefield, Tiggemann \& Winefield, 1991). Further, there is some evidence 
that lowered levels of self-esteem contribute to prolonging the individual's return to the workforce (Kasl, 1982).

Several studies have also evaluated self-esteem outcomes for unemployed people who attend training programs. Muller (1992) studied the effects of personal development courses on unemployed women's level of self-esteem and depression and found that participants improved significantly more on both than the control group. Self-esteem benefits from the course were maintained at follow-up. Creed, Hicks and Machin (1998) evaluated psychological outcomes for unemployed people who attended occupational skills training programs. Unemployed trainees improved on a range of well-being variables, including selfesteem, compared to a waiting list control group. No long-term benefits to self-esteem were identified in this study.

\section{Self-efficacy and Self-esteem}

Branden (1969) argued that belief in one's capacity to change one's own situation was a major determining factor in the level of self-esteem. For the unemployed individual, jobsearch confidence or self-efficacy is intimately associated with the capacity to change one's situation, and has been the behaviour most often examined in the literature. Whereas selfesteem has widely been used as a measure of well-being, self-efficacy has more typically been utilised as a predictor of behaviour, usually job-seeking behaviour (Wenzel, 1993). In this sense, self-efficacy can be viewed as a catalyst for an increase in well-being. Confidence in one's ability to find employment is likely to increase the level of well-being, including self-esteem.

The experimental evidence is that self-efficacy has a strong effect on the tasks a person will undertake, the effort they bring to bear on these tasks, their perseverance, their response to set-backs, and has been found to be influential in changes across a wide range of 
behaviours (Bandura, 1997). It is an important consideration for unemployed people, for if individuals were to have a high level of self-efficacy for finding a job, they would, for example, be more likely to continue to search for a job even in the face of knock-backs.

Few studies have compared levels of self-efficacy of unemployed with employed individuals. In contrast, the effects of training on self-efficacy have been examined. For example, Eden and Aviram (1993) evaluated the outcomes of a training intervention for unemployed individuals where the main aim was to raise job-search efficacy. Self efficacy levels were found to be associated positively with looking for work and with reemployment, and participants whose self efficacy was raised by the training increased their job-search behaviours and were more likely to go on to become re-employed. The effects of self-efficacy on training outcomes for unemployed people have also been examined. Phelps and Creed (1995) found that self-efficacy was able to predict performance outcomes of training and levels of satisfaction at follow-up for unemployed trainees. In this study, participants with lower levels of efficacy were also more likely to drop out of training.

\section{Behavioural Plasticity}

It is to be expected that people attending training do not respond in an homogenous way. Brockner (1988) developed an explanation for why individuals with different levels of wellbeing should respond in different ways. Brockner specifically examined self-esteem, and argued that those with lower levels of self-esteem would be more responsive to external cues, especially social cues, and thus should respond differently to situations, that is, be more "behaviourally plastic". This theory of behavioural plasticity has been tested directly with unemployed populations. Creed et al. (1998) found that long-term unemployed individuals who had lower levels of self-esteem when they began a training course improved more on self-esteem than did those with higher initial levels. Eden and Aviram (1993) also 
found support for this theory in the area of self-efficacy with their self-efficacy training course for the long-term unemployed. They found that those who had lower levels of selfefficacy before training improved more than did those with higher levels.

\section{Psycho-social Climate}

Educators in traditional school settings have examined student perceptions of their learning environment in relation to achievements and well-being (Fraser, 1991; Fraser \& Walberg, 1991). Classrooms have been modified to bring about changes in student attitudes (Fraser \& Fisher, 1982), and one report has indicated associations between the classroom environment and levels of anxiety (Fraser, Pearce \& Azmi, 1982). The scales used to measure such learning environments tap three general dimensions that Moos (1974) argued conceptualized all human environments. These dimensions overlap with the latent functions proposed by Jahoda (1981), and include (with Jahoda's corresponding latent functions in brackets): (a) Relationship dimensions (social contact), (b) Personal Growth dimensions (imposed goals and purposes, status), and (c) System Maintenance dimensions (time structure and enforced activity). One study, Creed, Hicks and Machin (1996) that evaluated training outcomes for unemployed people found associations between training climate and well-being, and between training climate and improvements in well-being. These outcomes lend support to the notion that training programs for the unemployed operate to replace latent functions that are missing for individuals without work and which mediate their wellbeing. 


\section{Summary and Research Questions}

From the above, there is consensus that there is a link between unemployment and poor well-being, and that deterioration in well-being is largely caused by the individual's unemployment situation.

The evidence in relation to outcomes for training interventions for unemployed people is more equivocal. Some evaluations have identified benefits for participants, and in some reports these benefits have persisted after training has ended. The present study will examine confidence and well-being outcomes for unemployed people who attended occupational skills/personal development training courses. In contrast to previous training evaluations for unemployed people, this study will examine long-term as well as short-term outcomes by comparing participant outcomes with outcomes of a waiting-list control group.

Further, participants in training programs do not and cannot be expected to respond to training in a uniform manner. Some evidence has been presented that suggested that unemployed people with higher levels of psychological distress and lower levels of confidence respond differently to training than higher functioning participants. The present study will examine outcomes for different levels of psychological functioning to test the behavioural plasticity theory as an explanation for training outcomes on these variables.

Lastly, evidence has been presented that a range of psychological variables, including well-being, has been associated with the psychosocial environment, and that one study (Creed et al., 1996) has identified associations between well-being, and changes in wellbeing, for an unemployed group attending training. The present study will examine the association between unemployed trainee's perceptions of the training environment and the variables of well-being and confidence to test for the impact of Jahoda's (1981) latent functions on well-being and confidence outcomes. 


\section{Method}

\section{Participants}

A total of 161 unemployed individuals from the south-eastern part of Australia participated in the study. Experimental participants were 109 course trainees, consisting of 43 males (39\%), 65 females (60\%), with one not identifying gender. Mean age was 28.58 years $(S D=9.80$; Range $17-49$ years $)$, and average length of unemployment was 12.82 months $(S D=11.06)$. Control participants were 53 unemployed individuals, 27 males $(52 \%)$ and 25 females (48\%), who met the same eligibility criteria for training as the experimental participants but were not attending a course. Their average age was 25.98 years $(S D=8.05$; Range 17-47 years), and had been unemployed on average for 6.88 months $(S D=5.94)$.

\section{Course Description}

Courses were federally funded programs specifically designed for unemployed people. The courses were conducted by community training agencies and included a combination of generic occupational skills training (e.g., computer and keyboard skills), specific occupational skills training (e.g., warehousing, retail), and personal development training to assist participants prepare for job interviews and impending jobs (e.g., grooming, selfconfidence). Courses ran full-time for periods of four to six weeks, and were classroom based.

\section{Measures}

Self-esteem. The Rosenberg Self-esteem Scale (RSE) (Rosenberg, 1965) was used to provide a measure of global self worth. The RSE contains 10 items (e.g., "I feel that I have a number of good qualities"), and participants were asked to rate how strongly they agreed or 
disagreed with each. Answers were scored on 1-4 scale using descriptors of "Strongly Agree" tp "Strongly Disagree". This gave a possible range of 10-40, with lower scores indicating greater self worth. The RSE has been widely used in occupational studies, including research using unemployed samples (e.g., Pernice \& Long, 1996). In the present study, internal consistency alpha levels were .87 (Time 1), .90 (Time 2), and .91 (Time 3), for all participants combined.

Job-search Self-efficacy. The Job-Procurement Self-Efficacy Scale (JPSE) (Wenzel, 1993) was used as a measure of job seeking confidence. The JPSE consists of 25 items (e.g., "I am unsure about how to make a good impression during a job interview"). Participants were asked to indicate their agreement with each item on a five-point scale that ranged from "Not at all like me" to "Very much like me". Scores on this scale can range from 0-100, with higher scores indicating higher levels of efficacy. In a longitudinal study, Wenzel reported internal consistency levels of .91 (T1) and .92 (T2). In the present study, the alpha coefficients were .91 (T1), .92 (T2), and .96 (T3), for all participants combined.

Psycho-social Training Environment. At T2 only, course participants were administered a modified 25-item short form of the Individualised Classroom Environment Questionnaire (ICEQ) (Fraser, 1990) to gauge the actual climate of the training room. Modifications included minor changes that allowed the scale to be used with unemployed adults rather than students (e.g., teacher was replaced with trainer). The ICEQ contains five sub-scales that provide measures across the three Moos (1974) general dimensions. The sub-scales are (i) Personalisation (opportunity to interact with trainer), (ii) Participation (encouragement to participate in the training room), (iii) Independence (control over learning), (iv) Investigation (encouragement of individual problem solving), and (v) Differentiation (individual treatment of trainee). The ICEQ has been used in Australian and overseas educational studies. Internal reliabilities reported for the five scales are in the range of 0.69 
to 0.85 (Fraser). In the present study, alpha levels for the five scales were .79 (Personalisation), .71 (Participation), .71 (Differentiation), .71 (Independence), and .74 (Investigation). The latter three reliability alphas were achieved by removing one item from the sub-scale in the cases of Differentiation (Q25) and Independence (Q8), and by removing two items from the Investigation sub-scale (Q4 \& Q19).

\section{Procedure}

The design can be considered pre-test/post-test quasi-experimental with follow-up, and utilising a non-equivalent control group to make comparisons with the training condition (Judd, Smith, \& Kidder, 1991). Participants were assigned to the intervention and control conditions in a naturally occurring manner. Measures of the dependent variables of selfesteem (RSE) and job-search self-efficacy (JPSE) were made prior to the exposure to the intervention, after exposure, and at 3-months follow-up. A measure of training climate (ICEQ) was obtained after exposure to the intervention. Questionnaires were administered to participants in the experimental condition in person early on the first day of the course (T1: RSE \& JPSE), on the last day (T2: RSE, JPSE \& ICEQ), and at 3-months follow-up (T3: RSE \& JPSE). Control participants were administered the T1 questionnaire in person (RSE \& JPSE), and received the T2 and T3 questionnaire (RSE \& JPSE) by mail. Seventyone $(65 \%)$ course participants and $30(58 \%)$ control participants responded at T2. Thirtytwo (45\%) course participants and $16(53 \%)$ control participants responded at T3. 


\section{Results}

\section{Comparisons between Experimental and Control Groups at Time 1}

Experimental and control groups did not differ at Time 1 on the dependent variables of self-esteem or job-search self-efficacy. The two groups also did not differ at T1 on the demographic variables of age or gender. Experimental participants were unemployed longer ( $M=12.82$ months) than the control group $(M=6.88$ months $), t(127)=3.22, p<.01$. The response rate to the length of unemployment question was considerably lower $(80 \%)$ than responses generally which raises at least some doubts about this comparison. In summary, few differences were identified between the experimental and control groups, indicating the usefulness of the controls for comparison. Descriptive statistics are presented in Table 1.

\section{Training Course Attrition T1-T2}

There were no significant differences between experimental participants who dropped out of the study after T1 and those who completed T1 and T2 questionnaires on any of the demographic (age, length of unemployment, sex) or dependent variables (RSE, JPSE). Similarly, there were no significant differences between the control participants who dropped out at T2, and those who did not. In summary, no attrition bias was identified. 
Table 1

Summary Data for Self-esteem and Job-search Self-efficacy at T1-T3, and for Psycho-social Training Environment at T2.

Experimental Group

Variable

$M \quad S D \quad n$

$M \quad S D \quad n$

\begin{tabular}{|c|c|c|c|c|c|c|c|c|}
\hline \multirow{3}{*}{\multicolumn{2}{|c|}{ RSE }} & $\mathrm{T} 1$ & 30.67 & 6.25 & 109 & 29.98 & 5.72 & 52 \\
\hline & & $\mathrm{T} 2$ & 31.46 & 6.36 & 71 & 28.53 & 6.12 & 30 \\
\hline & & $\mathrm{T} 3$ & 29.53 & 6.25 & 32 & 31.19 & 5.46 & 16 \\
\hline \multirow{3}{*}{\multicolumn{2}{|c|}{ JPSE }} & $\mathrm{T} 1$ & 63.23 & 17.85 & 105 & 68.84 & 14.93 & 51 \\
\hline & & $\mathrm{T} 2$ & 68.46 & 16.66 & 70 & 65.53 & 13.63 & 30 \\
\hline & & $\mathrm{T} 3$ & 64.56 & 21.28 & 32 & 69.25 & 14.12 & 16 \\
\hline \multicolumn{9}{|l|}{ ICEQ } \\
\hline & $\mathrm{A}$ & $\mathrm{T} 2$ & 20.24 & 3.05 & 64 & & & \\
\hline & E & $\mathrm{T} 2$ & 20.41 & 3.44 & 64 & & & \\
\hline & $\mathrm{D}$ & $\mathrm{T} 2$ & 15.38 & 3.39 & 63 & & & \\
\hline IV & V & $\mathrm{T} 2$ & 9.32 & 2.26 & 63 & & & \\
\hline & DI & $\mathrm{T} 2$ & 12.02 & 3.46 & 63 & & & \\
\hline
\end{tabular}

Note $:$ RSE $=$ Rosenberg Self-esteem Scale; JPSE = Job-procurement Self-efficacy Scale; ICEQ = Individualised Classroom Environment Questionnaire (Short Version); PA = Participation; PE = Personalisation; ID = Independence; IV = Investigation; DI = Differentiation. 
Correlations among Variables at T1

Correlations among the demographic and dependent variables at $\mathrm{T} 1$ are presented in Table 2 . The only significant coefficient above 0.30 was the negative association between self-esteem and job-search self-efficacy $(r=-.50, p<.01)$. Lower scores on the RSE selfesteem scale indicated higher self-esteem, while higher scores on the job-search selfefficacy scale (JPSE) indicated more job-search self-efficacy. This negative correlation means that those with higher self-esteem also reported higher levels of job-search selfefficacy. The relationship between age and length of unemployment approached this criterion, with older unemployed more likely to be unemployed longer.

Table 2

Pearson Product-Moment Correlations among demographic and dependent variables at T1

$\begin{array}{lllll}\text { Variables } & 1 & 2 & 3 & 4\end{array}$

1. Age

2. Length of Unemployment

3. RSE

4. JPSE
$-$

$.27 * *$

$.18^{*}$

.06 $--\quad-.50 * *$

.04

$\begin{array}{lll}-- & .06 & -.08\end{array}$

Note 1: RSE = Rosenberg Self-esteem Scale; JPSE = Job-procurement Self-efficacy Scale

Note $2: * p<0.05 ; * * p<0.01$ 
Effects of Course on levels of Self-esteem and Job-search Self-efficacy

To measure the effect of participating in the training course on self-esteem, a group (experimental vs. control) by time (T1-T2) mixed ANOVA was performed. No significant main effects were identified. There was a significant group by time interaction effect, $F(1$, $99)=4.97, p<.05$. Simple effects analysis revealed no difference between experimental and control groups at $\mathrm{T} 1$, a significant difference at $\mathrm{T} 2, F(1,99)=4.58, p<.05$, no T1-T2 difference for the control group, and no T1-T2 difference for the experimental group. The significant interaction effect was accounted for by an improvement in self-esteem for the experimental group, and a decline by the control group (see Figure 1).

To determine the effects of the training course on job-search self-efficacy, a second group (experimental vs. control) by time (T1-T2) mixed ANOVA was performed. No significant main effects were identified, but there was a significant group by time interaction effect, $F(1,95)=14.12, p<.001$. Simple effects analysis revealed a significant difference between the experimental and control groups at $\mathrm{T} 1, F(1,95)=6.51, p<.05$, no difference at T2, a significant difference between T1-T2 for the experimental, $F(2,94)=18.28718, p<$ .001 , and no difference between T1-T2 for the control group. The significant interaction effect was accounted for by an improvement in job-search self-efficacy by the experimental group and a decline by the control group (see Figure 2). Descriptive data for these analyses are presented in Table 3. 
Table 3

Summary Data for Self-esteem and Job-search Self-efficacy at T1-T2

\begin{tabular}{|c|c|c|c|c|c|c|c|}
\hline \multirow[b]{2}{*}{ Variable } & & \multicolumn{3}{|c|}{ Experimental Group } & \multicolumn{3}{|c|}{ Control Group } \\
\hline & & $M$ & $S D$ & $n$ & $M$ & $S D$ & $n$ \\
\hline \multirow[t]{2}{*}{ RSE } & $\mathrm{T} 1$ & 30.07 & 6.08 & 71 & 30.37 & 5.46 & 30 \\
\hline & $\mathrm{T} 2$ & 31.46 & 6.36 & 71 & 28.53 & 6.12 & 30 \\
\hline \multirow[t]{2}{*}{ JPSE } & $\mathrm{T} 1$ & 61.59 & 16.83 & 68 & 70.28 & 11.04 & 29 \\
\hline & $\mathrm{T} 2$ & 69.03 & 16.55 & 68 & 65.76 & 13.82 & 29 \\
\hline
\end{tabular}

Note $:$ RSE $=$ Rosenberg Self-esteem Scale; JPSE $=$ Job-procurement Self-efficacy Scale

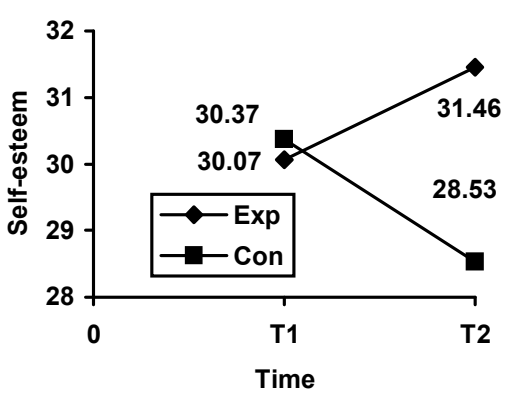

Figure 1: Mean scores for experimental and control groups at T1 and T2 for Self-esteem. 


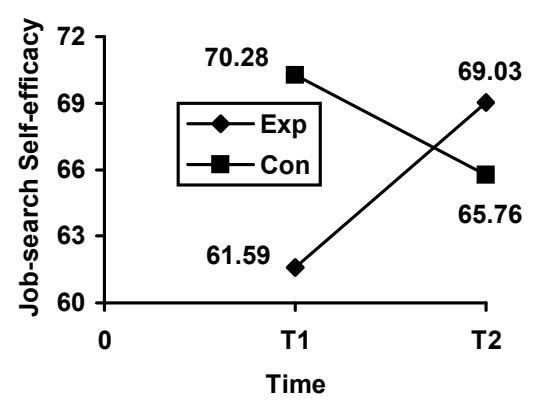

Figure 2: Mean scores for experimental and control groups at T1 and T2 for job-search selfefficacy

\section{Behavioural Plasticity}

In order to test whether course participants with lower levels of self esteem at T1 responded differently to the training program than those with higher levels at $\mathrm{T} 1$, a group (lower vs. higher level of self-esteem) by time (T1-T2) repeated measures ANOVA was performed. Lower and higher levels of self-esteem were identified by a median split on scores at $\mathrm{T} 1$. The results produced no significant group effect, a significant time effect, $F(1$, $69)=80.44, p<.01$, and a significant group by time interaction effect, $F(1,69)=8.00, p<$ .01 . The lower self-esteem group improved significantly between T1-T2, $t(37)=-3.40, p<$ .01 , whereas there was no significant T1-T2 change for the higher self-esteem group (see Figure 3). A similar analysis was conducted to test for behavioural plasticity effects for jobsearch self-efficacy. Significant effects for group, $F(1,66)=20.97, p<.01$, time, $F(1,66)=$ $64.28, p<.01$, and group by time interaction, $F(1,66)=16.67, p<.01$, were identified. There was a significant change between T1-T2 for the lower self-efficacy group, $t(32)=-$ $5.75, p<.01$, but no change across time for the higher self-efficacy group (see Figure 4). Descriptive data for these analyses are presented in Table 4. 
Table 4

Summary Data for Median Split on Self-esteem and Job-Search Self-Efficacy at T1 and T2 for Experimental group

\begin{tabular}{|c|c|c|c|c|c|c|c|}
\hline \multirow[b]{2}{*}{ Variable } & & \multicolumn{3}{|c|}{ Lower Scoring Group } & \multicolumn{3}{|c|}{ Higher Scoring Group } \\
\hline & & $M$ & $S D$ & $n$ & $M$ & $S D$ & $n$ \\
\hline \multirow[t]{2}{*}{ RSE } & $\mathrm{T} 1$ & 25.47 & 3.81 & 38 & 35.36 & 3.19 & 33 \\
\hline & $\mathrm{T} 2$ & 28.66 & 5.81 & 38 & 34.70 & 5.42 & 33 \\
\hline \multirow[t]{2}{*}{ JPSE } & $\mathrm{T} 1$ & 47.42 & 9.27 & 33 & 74.94 & 9.95 & 35 \\
\hline & $\mathrm{T} 2$ & 61.88 & 15.73 & 33 & 75.77 & 14.52 & 35 \\
\hline
\end{tabular}

Note $:$ RSE $=$ Rosenberg Self-esteem Scale; JPSE $=$ Job-procurement Self-efficacy Scale

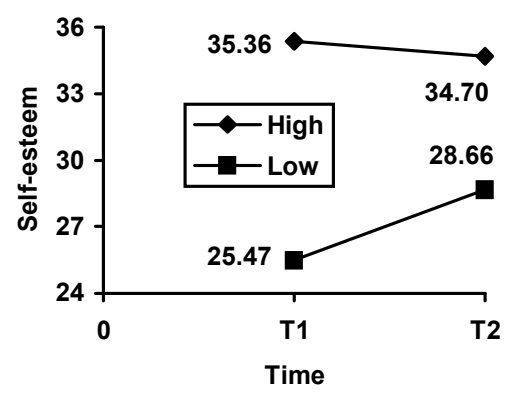

Figure 3: Mean scores for higher and lower self-esteem groups at T1 and T2. 


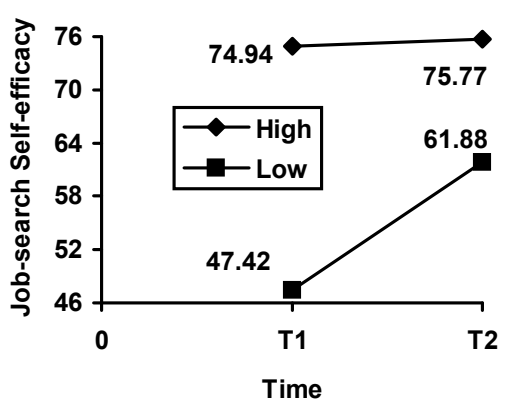

Figure 4: Mean scores for higher and lower job-search self-efficacy groups at T1 and T2.

Association between Training Climate, Self-esteem and Job-search Self-efficacy at T2

To test whether the psycho-social training climate was associated with levels of selfesteem or self-efficacy at the end of the course, Pearson Product-Product correlations were calculated between ICEQ scores and self-esteem and self-efficacy for all trainees at T2. Significant associations were found between self-esteem and the Personalisation sub-scale and the Investigation sub-scale. Similarly, significant associations were found between jobsearch self-efficacy and the same two sub-scales. These correlations are presented in Table 5. The evidence here is that at the end of training there was an association between selfesteem and the psychosocial training climate, and between self-efficacy and the training climate. Those with high levels of self-esteem and those with high levels of job-search selfefficacy viewed their training climate as one in which they could interact with trainers on a personal level, and which fostered trainee inquiry and exploration. 
Table 5

Pearson Product-Moment Correlation Coefficients calculated between Training Climate and Self-esteem and Job-search Self-efficacy at T2, and between Training Climate and Lower and Higher Scorers on Self-esteem and Job-search Self-efficacy

\begin{tabular}{lccccc}
\hline & Participation & Personalisation & Independence & Investigation & Differentiation \\
\hline RSE & .16 & $.34^{* *}$ & .14 & $.40^{* *}$ & -.05 \\
& $(n=64)$ & $(n=64)$ & $(n=63)$ & $(n=63)$ & $(n=63)$ \\
JPSE & .23 & $.28^{*}$ & .14 & $.35^{* *}$ & .06 \\
& $(n=63)$ & $(n=63)$ & $(n=62)$ & $(n=62)$ & $(n=62)$ \\
\hline
\end{tabular}

Note 1: RSE = Rosenberg Self-esteem Scale; JPSE $=$ Job-procurement Self-efficacy Scale

Note $2: * p<0.05 ; * * p<0.01$

Association between Training Climate and T1-T2 changes in Self-esteem and Job-search Self-efficacy

To determine if improvements in self-esteem and job-search self-efficacy were associated with perceptions of the psychosocial training climate, Pearson Product-Moment correlations were calculated between ICEQ scores at T2 and T1-T2 difference scores for self-esteem and self-efficacy. No significant associations were identified from this analysis. This meant that while there were associations between self-esteem and the training climate at $\mathrm{T} 2$, and between self-efficacy and the training climate at $\mathrm{T} 2$, there was little association between changes in the dependent variables and the training climate. 


\section{Course follow-up}

Of the 101 participants (71 experimental, 30 control) who completed a questionnaire at T2, 48 (48\%, 32 experimental, 16 control) responded at T3. No attrition bias was identified based on the dependent variables. However, those who responded at T3 were older $(M=$ 30.52) than those who $\operatorname{did} \operatorname{not}(M=26.04), t(96)=2.34, p<.05$, and were more likely to be female, $\chi^{2}(1)=7.37, p<.01$.

Forty-eight participants responded at $\mathrm{T} 3$. This represented a retention rate of $48 \%$ from $\mathrm{T} 2$, and comprised 32 (45\% retention rate) trainee participants and 16 (53\% retention rate) control group participants. Twenty-three $(48 \%)$ of these T3 respondents (18 trainees \& 5 control) indicated that they remained unemployed, while $25(52 \%)$ respondents (14 trainees \& 11 control) stated they were no longer unemployed, and reported a range of occupational statuses, singly and in combination, including full-time, part-time, casual employment, and attending a training course. At T1, those participants who remained unemployed at T3, did not differ from those who reported not being unemployed at T3, on length of unemployment, gender or level of self-esteem. However, those who ended up in employment at T3 had higher levels of job-search self-efficacy $(M=68.92)$ than those who were unemployed $(M=54.96), t(45)=-3.09, p<.01$, and were younger $(28.00$ vs. 34.09 years), $t(46)=2.16, p<.05$. A chi-square analysis indicated that there was no difference in employment rates at T3 between experimental and controls participants $(p>.05)$. Lastly, a series of one-way ANOVA's was conducted to determine whether the four groups of participants at T3 (unemployed trainees, employed trainees, unemployed controls, employed controls) differed in their response to the training course. This analysis was conducted using T1-T2 difference scores for self-esteem and job-search self-efficacy. For self-efficacy, no differences were identified on training outcomes between the T3 unemployed and T3 employed trainees $(p>.05)$. There was a significant difference on response to the training 
period between the T3 unemployed trainees $(M=13.00)$ and the T3 unemployed control participants $(M=-13.20)$, indicating that the unemployed trainees benefited from the training when compared to the unemployed control participants, $F(3,43)=4.19, p<.05$.

To test whether the gains made at $\mathrm{T} 2$ as a result of training were maintained, paired sample $t$-tests were conducted for trainees for both dependent variables. No differences were demonstrated between T2-T3 scores on either self-esteem or job-search self-efficacy, indicating no change from T2 to follow-up. The question still remained whether these 18 unemployed experimental participants responded to the training course in a similar way to the total group of experimental participants. Paired sample $t$-tests indicated that for this group, there were no significant changes in self-esteem, but a significant improvement in job-search self-efficacy (T1, $M=49.88 ; \mathrm{T} 2 M=62.88), t(16)=-3.37, p<.01$.

\section{Discussion}

\section{Effect of Training on Self-esteem and Job-search Self-efficacy}

This study found that training improved the self-esteem of trainees. Previous evidence in relation to global self-esteem has been equivocal, with some authors identifying benefits (e.g., Creed et al., 1998) while others have not (e.g., Harry \& Tiggemann, 1992). It has been suggested that occupational experiences may not impact on self-esteem and that this aspect of psychological health may be influenced in other ways (Mean Patterson, 1997). This was not the case with in this study.

The current findings also lend support to Jahoda's Deprivation theory. Manifest functions clearly played a minor role, if any, in the improvements to well-being brought about by the training. Unemployed trainees in this study were receiving no monetary reward for attending the training, suggesting that the benefits derived were influenced by other, 
latent functions. The most likely explanation here is that the latent functions provided by work (such as time structure) are also provided by other settings, in this case a training course, and are influential in improving well-being. The practical implications here are that unemployed people attending occupational skills training will gain benefits over and above work skills that are acquired by having some of the negative effects of unemployment ameliorated.

The evidence in respect to job-search self-efficacy is less clear. A significant interaction effect was found for self-efficacy, and post-hoc tests indicated that job-search self-efficacy did increase significantly over the training period for course participants. However, the control group recorded significantly higher efficacy scores at $\mathrm{T} 1$, and there were no differences between the two groups at the end of training. The most probable explanation still is that efficacy improved for course participants because of the training. Job-search selfefficacy has been shown to improve by targeting specific courses at this variable (Eden \& Aviram, 1993; van Ryn \& Vinokur, 1992). There is support here for the proposition that job-search self-efficacy will also improve when unemployed people attend occupational skills training programs that do not specifically offer training in building confidence.

\section{Behavioural Plasticity Effects}

Participants with higher levels of self-esteem at T1 (i.e., the lower scoring median-split group) declined significantly over the period of training. No significant change was identified for those with lower levels of self-esteem. This result may reflect an artefact of the study with the change representing a 'convergence to the mean'. It may also mean that for high well-being participants training courses have a toxic effect that results in deterioration. In the case of job-search self-efficacy, participants with lower levels at T1 responded differently to the course than those with higher levels, by showing greater 
improvement. This result is consistent with findings for courses that specifically target efficacy (Eden \& Aviram, 1993), and has been demonstrated here for training where the focus was on labour market activities rather than enhancing confidence. This is an important finding as it indicates that trainees will benefit differentially in relation to self-efficacy as a result of training, and has implications for course selection, program development and policy in relation to these training programs. Given the results in this section for self-esteem, however, the result for self-efficacy needs to be treated cautiously, and further studies are needed to resolve the issue.

Training Climate, Self-esteem and Job-search Self-efficacy

For trainees, there were significant associations between the self-esteem and training climate dimensions (Personalisation \& Investigation) at T2. Those with higher self-esteem were more likely to view the trainer as approachable on personal matters or issues other than those dealt with on the course, and to see the trainer as encouraging personal investigation and problem solving. Similar associations were found between job-search self-efficacy and climate (Personalisation \& Investigation) at T2. Consistent associations, then, were found between two training climate dimensions (Personalisation \& Investigation) and self-esteem and job-search self-efficacy. Little association was identified between training climate and changes in self-esteem or self-efficacy.

One other study (Creed, Hicks \& Machin, 1996) has identified associations between well-being variables and training climate, and changes in well-being variables and climate. These authors also found that Participation also correlated with well-being. The present findings add support to Jahoda's theory as an explanation for training outcomes, as they suggest that there is an association between participants' well-being and confidence (and to a lesser extent changes in esteem and confidence), and their views of the training 
environment. This indicates that supportive and encouraging interpersonal relationships in the training room between trainer and trainee are associated with better well-being and confidence, implying that trainers and training providers need to be cognizant of the association between their training climate and well-being levels for their unemployed participants.

\section{Post-course Evaluation}

The evidence in relation to maintaining self-esteem and self-efficacy gains is that, for the cohort of course participants who responded across the three times, self-efficacy improved as a result of attending the course and these gains were maintained at T3. This T1-T3 cohort did not improve significantly on self-esteem during the course, and demonstrated no changes on this variable at follow-up. That participant's confidence levels could be raised and maintained reflect well on the usefulness of these types of courses. This is an important finding as it indicates that benefits can persist despite the individual leaving the training environment, as has been found in other studies (Creed et al., 1998).

Course participants who self-classified at T3 follow-up as employed were more likely to be younger and to have higher levels of job-search self-efficacy prior to training. This implicates job-seeking self-efficacy as an important component in returning to work, and supports previous work which has identified this variable in this capacity (e.g., Eden \& Aviram, 1993). It is also likely to reflect an age bias in relation to job acquisition, although this needs to be further examined. Despite the above, there were no differences in return-towork rates between course participants and the control group. It has been demonstrated in this study that participants benefit in terms of improving well-being and confidence, however this was not translated into occupational advantages for participants. 


\section{Further Research}

Clearly, this is an important area for investigation. Training courses have been shown to improve well-being and confidence levels and need to be examined as to the mechanisms associated with these changes. The examination of trainees' perception of the training environment offers a fruitful avenue of research. Measures apart from those of environmental influences need also to be incorporated to test for other influences in this process. The examination of Personal Agency effects offers possibilities here. Despite problems with attrition rates, researchers need to persist with investigating long-term follow-up with this population to better determine psychological and occupational benefits associated with training. For example, do increases in job-search self-efficacy translate into increased job-search activities, and how do these impact on well-being and return-to-work? At a practical level, it needs to be determined what modifications to skills training courses would improve well-being and other psychological outcomes, or whether specific modules or courses need to be developed and attached to the skills based programs to achieve these purposes. 


\section{References}

Australian Bureau of Statistics. (2000a). Labour Force Australia. Preliminary Data.

Catalogue No 6202.0. Canberra: ABS; March.

Australian Bureau of Statistics. (2000b). Gopher:/gopher.statistics.gov.au, ABS Time Series, Labour Force, Unemployed Persons: Duration of Unemployment - Totals, Table 22.

Bandura, A. (1997). Self-efficacy: The exercise of control. New York: W.H. Freeman and Company.

Bednar, R.L., Wells, M.G., \& Peterson, S.R. (1989). Self-esteem: Paradoxes and innovations in clinical theory and practice. Washington: American Psychological Association.

Branden, N. (1969). The psychology of self-esteem: A new concept of mans psychological nature. Los Angeles: Nash Publishing.

Brockner, J. (1988). Self-esteem at work: Research, theory, and practice. Lexington, MA: Lexington Books.

Creed, P.A., Hicks, R., \& Machin, T. (1996). The effect of psychosocial training climate on mental health outcomes for long-term unemployed individuals. Australian and New Zealand Journal of Vocational Education Research, 4 (2), 26-39.

Creed, P.A., Hicks, R. E., \& Machin, M. A. (1998). Behavioural plasticity and mental health outcomes for long-term unemployed attending occupational training programmes. Journal of Occupational and Organisational Psychology, 71, 171-191.

Eatwell, J. (1999). Unemployment: National policies in a global economy. Occasional Paper: Queen's College, Cambridge.

Eden, D., \& Aviram, A. (1993). Self-efficacy training to speed reemployment: Helping people to help themselves. Journal of Applied Psychology, 78 (3), 352-360. 
Feather, N.T. (1990). The psychological impact of unemployment, New York: Springer.

Feather, N. T., \& O'Brien, G. E. (1986a). A longitudinal analysis of the effects of different patterns of employment and unemployment on school-leavers. British Journal of Psychology, 77, 459-479.

Fraser, B. J. (1990). Individualised classroom environment questionnaire: Handbook. Melbourne: Australian Council for Educational Research.

Fraser, B. J. (1991). Validity and use of classroom environment instruments, Journal of Classroom Interaction, 26(2), 5-11.

Fraser, B. J. \& Fisher, D. L. (1982). Predicting students' outcomes from their perceptions of classroom psycho-social environment. American Educational Research Journal, 19, 498518.

Fraser, B. J., Pearse, R. \& Azmi. (1982). A study of Indonesian students' perceptions of classroom psycho-social environment. International Review of Education, 28, 337-355.

Fraser, B. J. \& Walberg, H. J. (Eds.). (1991). Educational environments: Evaluation, antecedents, and consequences. Pergamon Press: London.

Fryer, D. M. (1986). Employment deprivation and personal agency during unemployment: A critical discussion of Jahoda's explanation of the psychological effects of unemployment. Social Behaviour, 1, 3-23.

Fryer, D. (1995). Labour market disadvantage, deprivation and mental health benefit agency. The Psychologist, June, 265-272.

Harry, J.M. \& Tiggemann, M. (1992). The psychological impact of work re-entry training for female unemployed sole parents. Australian Journal of Social Issues, 27(2), 7591. 
Henwood, F., \& Miles, I. (1987). The experience of unemployment and the sexual division of labour. In D. Fryer \& P. Ullah (Eds.). Unemployed people (pp. 94-110). Milton Keynes: Open University Press.

Jahoda, M. (1981).Work, employment and unemployment: Values, theories and approaches in social research. American Psychologist, 36 (2), 184-191.

Judd, C. M., Smith, E. R., \& Kidder, L. H. (1991). Research methods in social relations: Sixth edition. Fort Worth: Harcourt Brace Jovanovich College Publishers.

Kasl, S. V. (1982). Strategies of research on economic instability and health. Psychological Medicine, 12, 637-649.

Mean Patterson, L. J. (1997). Long-term unemployment among adolescents: A longitudinal study. Journal of Adolescence, 20, 261-280.

Moos, R. H. (1974). The Social Climate Scales: An Overview, Consulting Psychological Press: Palo Alto, California.

Muller, J. (1992). The effects of personal development training on the psychological state of long-term unemployed women. Australian Psychologist, 27(3), 176-180.

Patton, W., \& Noller, P. (1990). Adolescent self-concept: Effects of being employed, unemployed or returning to school. Australian Journal of Psychology, 42, 247-259.

Pernice, R. \& Long, N. (1996). Long-term unemployment, employment attitudes and mental health. Australian Journal of Social Issues, 31 (3), 311-326.

Phelps, M. \& Creed, P. A. (1996). Self-efficacy as a factor in job training performance and occupational satisfaction for unemployed individuals. Journal of Applied Social Behaviour, 2 (1), 44-63.

Rosenberg, M. (1965). Society and the adolescent self-image. Princeton, N.J.: Princeton University Press. 
Shamir, B. (1986). Self-esteem and the psychological impact of unemployment. Social Psychology Quarterly, 49 (1), 61-72.

Sheehan, P. (1980). Crisis in abundance. Ringwood: Penguin.

van Ryn, M \& Vinokur, A. D. (1992). How did it work? An examination of the mechanisms through which an intervention for the unemployed promoted job-search behaviour. American Journal of Community Psychology, 20 (5), 577-597.

Wanberg, C. R. Watt, J. D. \& Rumsey, D. J. (1996). Individuals without jobs: An empirical study of job-seeking behaviour and reemployment. Journal of Applied Psychology, 81. 76-87.

Warr, P.B. (1987). Work, unemployment and mental Health. Oxford: Clarendon Press.

Wenzel, S. L. (1993). The relationship of psychological resources and social support to job procurement self-efficacy in the disadvantaged. Journal of Applied Psychology, 23 (18): 1471-1497.

Winefield, A. H. (1995). Unemployment: it's psychological costs. In C. L. Cooper \& I. T. Robertson (Eds.). International Review of Industrial \& Organisational Psychology. Chichester: Wiley

Winefield, A. H., \& Tiggemann, M. (1990). Employment status and psychological wellbeing: A longitudinal study. Journal of Applied Psychology, 75(4), 455-459.

Winefield, A. H., Tiggemann, M., Winefield, H. R. (1991). The psychological impact of unemployment and unsatisfactory employment in young men and women: Longitudinal and cross-sectional data. British Journal of Psychology, 82, 473-486. 